\title{
Ultra-low-temperature district heating systems - a way to maximise the ecological and economical effect of an investment?
}

\author{
Bartłomiej Ciapała ${ }^{1, *}$, Jakub Jurasz ${ }^{2}$, Mirosław Janowski ${ }^{1}$ \\ ${ }^{1}$ AGH University of Science and Technology, Faculty of Geology, Geophysics and Environmental \\ Protection, Department of Fossil Fuels, 30 Mickiewicza Av., 30-059 Kraków, Poland \\ ${ }^{2}$ AGH University of Science and Technology, Faculty of Management, Department of Engineering \\ Management, 30 Mickiewicza Av., 30-059 Kraków, Poland
}

\begin{abstract}
One of the most challenging aspects of a new district heating (DH) design is its general performance, which will determine the ecological and economic impacts of the investment. Choosing the lowest applicable temperatures which are distributed via ultra-low-temperature district heating (ULTDH) systems may yield the desired results. The article elaborates the economic and ecological aspects of the application of ULTDH. The results of the analysis indicate that the capacity factor may be significantly improved, while the overall ecological effects of the investment are strongly dependent on the previously used heat source and the source of electric power.
\end{abstract}

\section{Introduction}

Establishing a new, local district heating (DH) network is a long and complex project, which, beside economic returns, should bring ecological benefits. This latter result is of increasing significance, especially in cases when public co-funding is expected/desired. There are a variety of possible activities which can influence the ecological effect of the investment, among others: the fuel/kind of energy used previously, efficiency of heat transmission and finally, the proposed source of energy for the DH system. Coincidentally, the same factors are crucial in determining the investment rate. The present article intends to describe economic and ecological advantages of ultra-low-temperature district heating (ULTDH).

The used model is described in detail in [1].

\section{Network description: applicability and temperature ranges}

For low- and ultra-low-temperature district heating, buildings technologically advanced heating area are most suitable, such as floor heating or forced-convection radiators. Although temperature ranges for ULTDH have not yet been clearly determined, it is certain that it will supply water at temperatures below $50^{\circ} \mathrm{C}$, which is insufficient for sanitary hot water

\footnotetext{
*Corresponding author: bciapala@agh.edu.pl
} 
preparation without additional heating [2], i.e. it is significantly lower than the usual temperature of district heating. The considerations in this paper will regard planned DHs rather than the modification of existing ones, although they are relevant in every instance. Such may be developed in areas of low development density, where it is especially important to limit heat losses in the pipeline. Ultra-low-temperature DHs may also be applied at the very end of the typical DH range, and supplied by return water. Other reasons for establishing ULTDH include the possibility of using DH as a heat sink for low-temperature industrial processes (including server cooling) and creating a real opportunity for efficient utilisation of renewable sources of energy [3-5].

In the article, the demand site which is considered is a low-temperature space heating system with supply temperature of $45^{\circ} \mathrm{C}$, a return temperature of $25^{\circ} \mathrm{C}$ and heat power demand of $80 \mathrm{~W} / \mathrm{m}^{2}$ at outdoor temperature $-20^{\circ} \mathrm{C}$. The temperature drop at the heat exchanger in the building is assumed to be $10 \mathrm{~K}$, and heating begins when the expected outdoor temperature in the next full 24 hours is lower than $10^{\circ} \mathrm{C}$. The mass flow is calculated for LTDH with a $20 \mathrm{~K}$ difference between supply and return and the maximum accepted deficit is $20 \%$ of overall space heating energy demand. The deficit is covered by electric heat source. Each and every enumerated parameter may be individually modified. The goal of this publication is to indicate and elaborate the improvements which may be brought by developing ultra-low-temperature district heating.

\section{Aspects of improvement}

\subsection{Ecological benefit}

As mentioned in the introduction, ecological benefits are important, not only for areas with air quality problems but for each investor who has obtained financial support from public funds. In case of ULTDH, the increase of ecological benefits may come from three directions.

Firstly, environmentally-friendly heat is more commonly available the lower its required temperature is. When $\mathrm{DH}$ requires a temperature lower than $50^{\circ} \mathrm{C}$, it may be supplied as waste heat by facilities such as server hubs, metal forming (not necessarily smelter plants), milk processing, food storages, i.e. comparatively common, existing facilities. Lower temperature requirements also facilitate the use of renewable sources of energy, as lowerenthalpy resources are more available $[6,3]$. Here, it is especially worth drawing attention to the possibility of using geothermal energy, by which we mean both geothermal water and heat obtained via ground-sourced heat pumps. Thus, ULTDH may facilitate the use of energy a near-zero carbon footprint. Nevertheless, even combustion of hydrocarbon fuels may perform better in cases of lower demanded supply temperature due to intensified water steam condensation in exhaust gases.

Secondly, decreased temperature inside the pipeline means weaker thermodynamic force, which is due to transferring heat outside the pipeline. In other words, for the same pipeline insulation and dimensions, and the same mass flow and ambient conditions, there will be less energy lost in the transportation of lower-enthalpy fluid [4]. This directly increases the efficiency of the $\mathrm{DH}$, and limits the production of energy destined never to reach the customer. Of course, compared to the LTDH, the lower the temperature of DH supply is, the higher the mass flow needed to provide the same heat power; thus, there is an optimum temperature, at which heat energy saved from being lost in the pipeline equals or exceeds the circulation pump's increased energy consumption (caused by higher mass flow). The optimum is dependent on multiple parameters - mainly on pipeline dimensions, class of insulation and efficiency and placement of the circulation pumps - and is thus very individual and not necessarily in the range of ULTDH. 
Thirdly, ULTDH may be a perfect heat sink not only for big, organised processes (detailed above), but also for individual customers, e.g. detached houses. It is particularly important for reducing $\mathrm{CO}_{2}$ footprint, which may be significant for cooling. The cooling capacity is various, depending on chosen supply temperature, heat source and constant heat demand.

The three elaborated main advantages of ULTDH in maximising investment ecological effect are difficult to quantitatively describe in general terms, and should instead be worked out taking into account current emission coefficients, including the energy consumption of individual peak-power electric heat sources.

\subsection{Economic benefit}

First of all, application of ULTDH may potentially decrease investment costs - although pipelines may be required to be bigger than in typical DHs (for present considerations - the supposed mass flow is the same as in case of LTDH (50/25)), it may be placed in significantly shallower trench, limiting the costs of earth works.

Secondly, the ULTDH is heavily used over the heating season, as shown in Fig. 1. during a typical meteorological year for Warsaw, there are 2,588 hours in which $\mathrm{DH}$ is at maximum power. Meanwhile, the differences between required power and power provided by the $\mathrm{DH}$ (here $-20 \%$ of the deficit) are supplied by an individual, electric peak power heat sources. Both ecologically and economically, use of electric energy will not necessarily decrease the economic and ecological effects of ULTDH - electric power may be provided by the ULTDH operator and be produced from renewable sources of energy. What is more, electric power causes dust emissions smaller by orders of magnitude from individual coal boilers. Here, it must be emphasised that only space heating during the heating season is taken into consideration. Including summer cooling and sanitary hot water preparation would significantly influence overall effects.

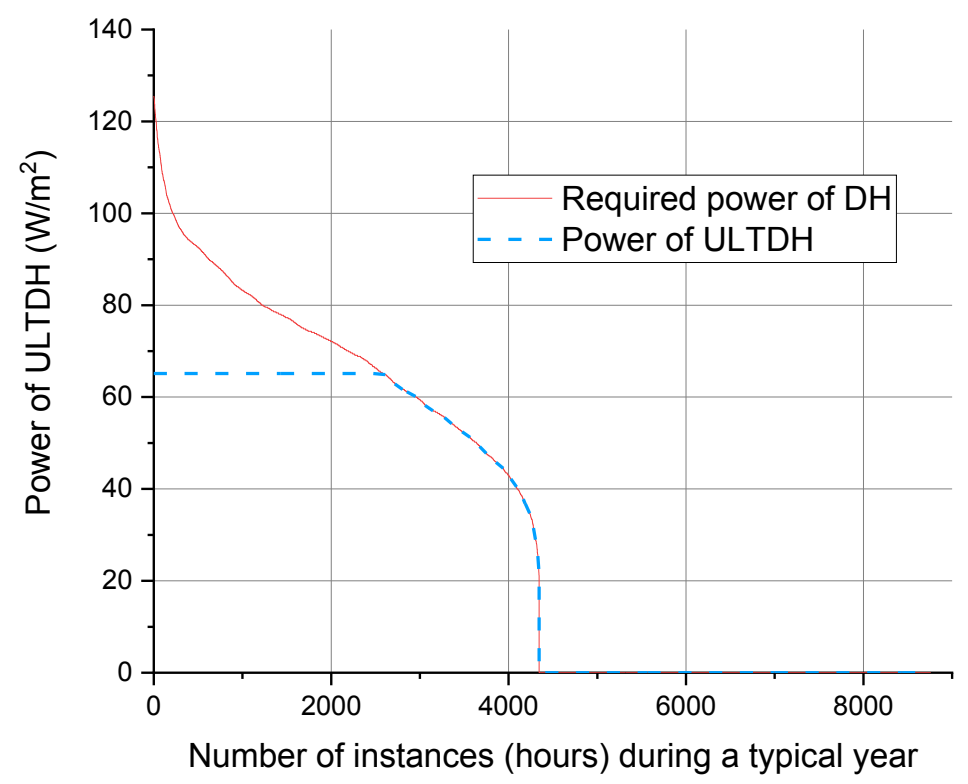

Fig. 1. Ordered heat demand versus ordered ULTDH system power output. The horizontal blue line indicates hours where, despite $100 \%$ DH power usage, the heat demand has not been entirely satisfied. 
Such a method of using DH provides a high capacity factor (CF), leading to higher investment rate, both for the pipeline and the heat source. What is more, the heat source works more effectively, because for a significant part of the year it works at full or almostfull load. Fig. 2 shows how CF changes with supply temperature. For the described space heating installation, there is a chance to obtain comparatively high CF for lower temperatures, although this leads to drastic energy deficits, making the entire investment pointless. For supply temperature higher than $45^{\circ} \mathrm{C}$, the decrease of energy deficit is comparatively low and, for low-temperature space heating systems, further increase of the supply temperature is not justified.

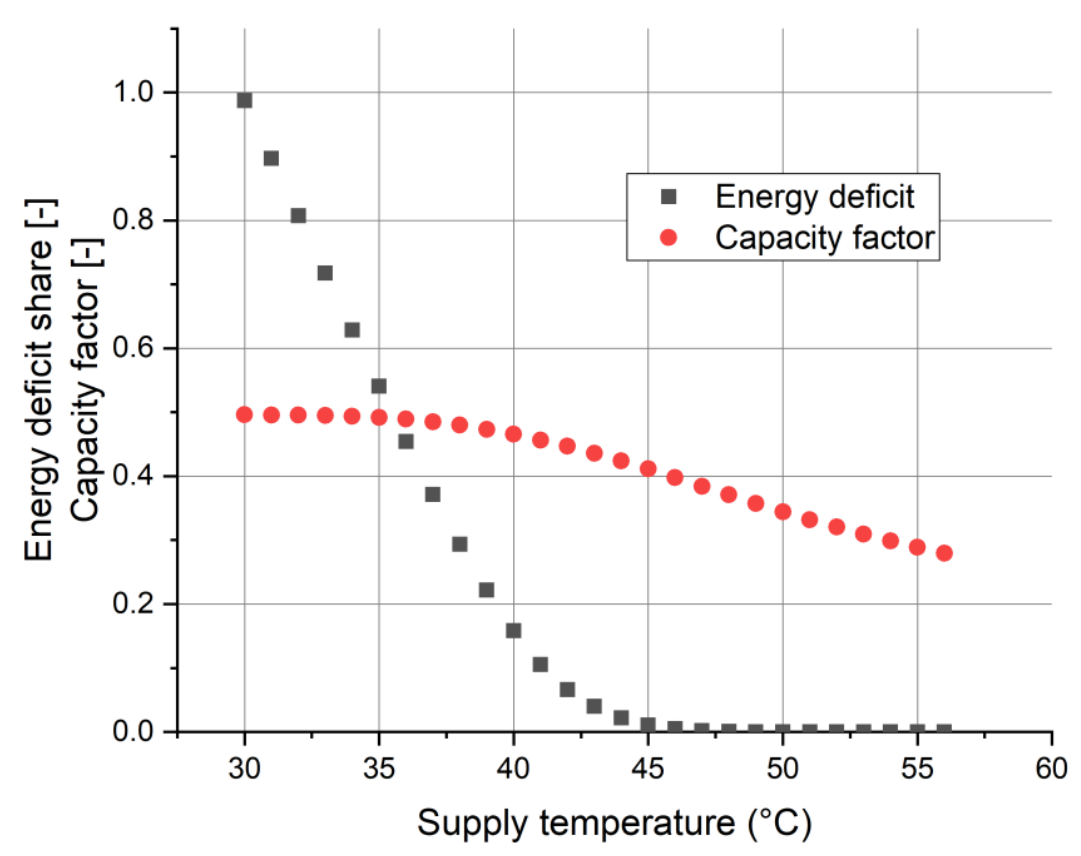

Fig. 2. Energy deficit versus capacity factor. There is a supply temperature, for which further increase does not provide significant change in energy deficit, simultaneously decreasing the capacity factor.

The possibility of waste heat usage mentioned above has two economic aspects. It not only allows cheap or even free-of-charge energy to be obtained and sold at regular prices, increasing profitability, but also reduces costs connected to heat source maintenance. In the case of a waste heat provider, investment costs are significantly reduced, too. Similar benefits come from using geothermal low-temperature heat, as existing wells and aquifers with low mineralisation may already be used, extensively reducing costs of investment and maintenance of wells, heat exchangers, etc. In Central Europe, temperatures required by ULTDH to satisfy $20 \%$ energy deficit limitation (in the case of Warsaw $-39.33^{\circ} \mathrm{C}$ ) are easily providable by installations consisting of solar collectors and heat storage units. This solution also limits maintenance costs, although investment costs are significant. 


\section{Summary}

There are various benefits of applying ULTHD. The main advantage is in the more effective use of heat available in communities or commonly existing in the nature - low-temperature renewable energy sources - but also the effective use of conventional fuels. This improves the financial condition of the energy company and has noticeable ecological effects. Due to the high capacity factor, the expected results calculated per length of pipeline, or nominal power output of the district heating system itself, will be higher than for a typical 80/60 district heating system. Although cost of the pipeline itself is likely to be lower than in the typical DH, the overall cost of the investment may be not lower, as heat exchangers in the buildings may need to be enlarged. Nevertheless, in order to calculate costs and ecological benefits, further consideration is required.

The paper prepared under AGH-UST statutory research grant No. 11.11.140.031.

\section{References}

1. B. Ciapała, M. Janowski and J. Jurasz, Techn. Poszuk. Geol., Geotermia, Zrównow. Rozwój, vol. in press (2018)

2. O. Gudmundsson, M. Brand and J. E. Thorsen, The 14th International Symposium on District Heating and Cooling, Stockholm (2014).

3. M. Brand, S. Svendsen, Energy, 62, pp. 311-319 (2013)

4. H. Li, S. J. Wang, Energ. Proc., 61, pp. 1472-1475 (2014)

5. U. Persson, S. Werner, Appl. Energy, 88, pp. 568-576, (2010)

6. D. Østergaarda, S. Svendsen, The 15th International Symposium on District Heating and Cooling (2017)

7. H. C. Gils, J. Cofala, F. Wagner and W. Schopp, Energy, 58, pp. 318-329 (2013)

8. M. Kimming, C. Sundberg, A. Nordberg and P.-A. Hansson, Energy Policy, 78, pp. 5161 (2015)

9. S. Nielsen and B. Moller, Energy, 57, pp. 458-468, (2013)

10. S. Pusat and H. H. Erdem, Energy and Buildings, 72, pp. 177-185 (2014) 